\title{
Field validation of fibre Bragg grating sensors for measuring strain on driven steel piles
}

\author{
P. DOHERTY*, D. IGOE*, G. MURPHY*, K. GAVIN*, J. PRESTON $\dagger$, C. McAVOY $\ddagger$, B. W. BYRNE $\S$, R. MCADAM $\S$,

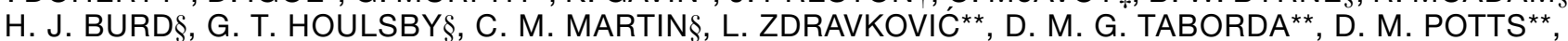

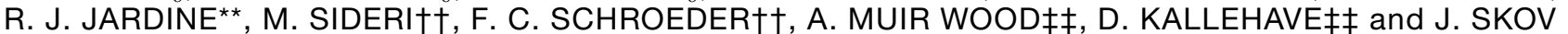
GRETLUND ‡キ

\begin{abstract}
In recent years, fibre Bragg grating (FBG) sensors have emerged as a relatively new strain sensing technology for civil engineering applications. This paper presents a field trial to assess the feasibility of using FBG sensor arrays to measure strain in driven steel piles. Two FBG arrays were installed in grooves within the wall of an open-ended steel pile such that the finished profile was completely flush with the pile shaft. The pile was then driven into a dense sand deposit using an impact hammer to provide the required installation energy. The FBG gauges were monitored throughout driving in conjunction with accelerometers to quantify the scale of the hammer impacts. The FBG sensors were subjected to hammer blows that yielded pile accelerations between $500 \mathrm{~g}$ and $1400 \mathrm{~g}$ during installation. The fibre optic sensors were measured throughout driving, where they were observed to respond to the hammer impacts, showing a rapid increase in strain and a return to their initial values between hammer strikes. After installation, a lateral load test was performed with independent load measuring devices. Excellent agreement was observed between the measured moments and those inferred from the FBG strain output. The output of this trial demonstrates that FBG strain sensors are a viable means of measuring load transfer in foundation systems and are suitably robust to withstand high pile driving accelerations.
\end{abstract}

KEYWORDS: field instrumentation; in situ testing; piles; soil/structure interaction

ICE Publishing: All rights reserved

\section{INTRODUCTION}

The PISA project is a joint-industry initiative aimed at developing new design guidelines for laterally loaded piles, for offshore wind turbines. This project involves a major field testing component involving high-moment lateral load tests on prototype scale steel piles up to $2 \mathrm{~m}$ in diameter. The experimental setup includes extensive instrumentation to capture the soil-pile behaviour, including the strain distribution along the shaft of the steel piles. At the conceptual stage of the project, a number of instrumentation schemes were assessed, including conventional electrical resistance bonded and welded gauges. However, installation of these standard components is complicated by the confined space within the pile and the requirement to install protective channels, which would likely affect the bending stiffness of the piles as well as the external shape of the pile. Fibre Bragg grating (FBG) sensors offered a viable alternative, not subject to the same constraints as conventional gauges, but with the drawback of being unproven technology under high impact accelerations associated with driven steel piles.

Manuscript received 31 December 2014; first decision 29 January 2015; accepted 8 March 2015.

Published online at www.geotechniqueletters.com on 13 July 2015.

*School of Civil, Structural and Environmental Engineering, University College Dublin, Belfield, Dublin, Ireland †Monitor Optics, Terenure, Dublin, Ireland

tLLoyd Acoustics Ltd, Craigavon, Northern Ireland

§University of Oxford, Oxford, UK

** Imperial College London, London, UK

†Geotechnical Consulting Group, London, UK

ttDONG Energy Wind Power, Copenhagen, Denmark
In order to assess this technology for the PISA project, a preliminary field validation trial was undertaken.

\section{FIBRE OPTIC SENSOR TECHNOLOGY}

The measurement of strain using optical fibres is considered to be an established monitoring technique. The sensing method used in this demonstration project is based on the use of FBGs. These are particular sections of an optical fibre that are very sensitive to the strain applied. As the Bragg grating period is influenced by external strains, the change in strain on the grating can be determined from the change in wavelength of light reflected from the grating. The wavelength-encoded nature of the output of FBG elements has a number of distinct advantages over direct intensity-based sensing schemes; most importantly, as the sensed information is encoded directly into wavelength, which is an absolute parameter, the output does not depend on the total light levels, losses in the connecting fibres and couplers, or source power (Kersey \& Morey, 1993). In this respect, they would have similar long-term stability to vibrating wire type strain gauges, without many of the drawbacks (such as fragility, large gauge size, low logging frequency).

By adopting the FBG technology, the following advantages to the project were envisaged.

- Their small size means they do not require welded channels for mechanical protection.

- The ability to house multiple sensors on a single string results in quicker installation time for a large number of sensors.

- Minimal noise and drift as there is no electrical excitation. 
Fibre optic sensors have been used successfully on a number of geotechnical instrumentation projects, for example the monitoring of tunnel linings (Cheung et al., 2010), embankment settlement (Zhu et al., 2008), bored piles (Lee et al., 2004) and jacked piles (Liu \& Zhang, 2012). However, FBGs have not been used to monitor driven steel piles and as a result there is concern about the survivability and robustness of the sensors under high impact accelerations and harsh pile driving conditions. The main objectives of the testing were

- to assess whether FBG sensors were sufficiently robust to survive driving

- to determine if the sensors could accurately determine the pile bending moment in a subsequent lateral load test.

\section{EXPERIMENTAL DESCRIPTION}

The demonstration project involved driving a $340 \mathrm{~mm}$ diameter instrumented test pile to a depth of $5 \mathrm{~m}$ at the University College Dublin (UCD) dense sand test bed site. The pile was instrumented with two FBG strings, with two sensors on each string (one near the pile base and one near the head). One week after installation, the pile was load tested laterally with a maximum applied load of $180 \mathrm{kN}$, resulting in approximately $1^{\circ}$ rotation at ground level. This corresponds to the serviceability limit state requirement for rotation of a typical offshore wind turbine at the foundation level.

\section{Fibre Bragg grating instrumentation}

The instrumentation used for the demonstrator can be summarised as follows.

- Sensing cables. The distributed FBG strain sensor cable used in the testing was a $1 \mathrm{~mm}$ glass fibre-reinforced polymer (GFRP) cable.

- Interrogation unit. An interrogation unit is required to measure the change in light wavelength reflected from the Bragg gratings. The interrogator used in the testing was a Micron Optics sm130 optical sensing interrogator based on fibre Fabry-Perot tunable filter technology. All module settings, sensor calculations, data visualisation, storage and alarming tasks were run on an external PC.

- Connection cables. These are used if the sensor locations are distant from the interrogation unit. The connection cables transfer the signals to the unit. The cables used were standard telecommunication-grade cables which were embedded in a GFRP cladding to provide sufficient protection for installation and operation in civil structures.

- Control and communication software. The system was controlled by specific software that manages the acquisition parameters and performs conversion of the optical measurements to the units of interest. The software also handles alerts and alarms that can be triggered using various logics, and can transmit these, along with the desired data, to a remote host or can be integrated with existing communication and control systems.

\section{Fibre sensor installation}

Two FBG strain sensor cables were installed on the test pile. The pile was a $340 \mathrm{~mm}$ diameter $12 \mathrm{~mm}$ thick steel pipe pile of total length $6.8 \mathrm{~m}$. The two sensor cables, each housing two FBG strain sensors, were installed diametrically opposite on the pile wall. The method for installing the gauges was as follows.

- The pile was marked up to ensure the channels were vertically oriented and diametrically offset.
- A $3 \mathrm{~mm}$ thick cutting disc was used to grind a channel $5 \mathrm{~mm}$ deep into the pile wall, terminating $200 \mathrm{~mm}$ before the toe end of the pile.

- Each channel was prepared using specialist degreasers, acids and neutralisers.

- Once the channels were prepared, the FBG sensor string was inserted and bonded in place using a two-part epoxy.

- Once the sensor string and epoxy were in place, the temperature of the pile was maintained above $20^{\circ} \mathrm{C}$, using heaters at either end of the pile, for a period of $12 \mathrm{~h}$ to ensure adequate bonding of the gauges.

The installation time for the sensor strings was extremely fast, with the second sensor string installed within half a day. It should also be noted that this installation time is independent of the number of sensors in each sensor string, potentially making this an extremely efficient strain measurement solution for the PISA project.

\section{Site description}

The load tests were conducted at the UCD sand test bed located in Blessington, Co. Wicklow, Ireland. The sand deposit at the site is heavily overconsolidated as a result of the glacial history and recent excavations. Detailed descriptions of the ground conditions at the site have been reported by Tolooiyan \& Gavin (2011) and Doherty et al. (2012). Sand replacement tests suggest that the in situ relative density is close to $100 \%$ and the unit weight of the soil is $20 \mathrm{kN} / \mathrm{m}^{3}$. Triaxial compression tests on reconstituted Blessington sand indicate the constant volume friction angle is $37^{\circ}$ and the peak friction angle decreases from $54^{\circ}$ at $1 \mathrm{~m}$ depth to $42^{\circ}$ at about $5 \mathrm{~m}$ depth. Multiple cone penetration tests were conducted in the vicinity of the test pile, and the averaged cone trip resistance $\left(q_{\mathrm{c}}\right)$ values increased from 10 $\mathrm{MPa}$ at shallow depths to $25 \mathrm{MPa}$ at $10 \mathrm{~m}$ depth, indicating the dense nature of the deposit.

\section{VALIDATION TEST PILE RESULTS}

On 10 January 2014 the FBG test pile, along with a $9 \mathrm{~m}$ long $340 \mathrm{~mm}$ diameter reaction pile, was driven into the UCD dense sand test site in Blessington. The instrumented pile was driven to $5 \mathrm{~m}$ depth with a Junttan $5 \mathrm{t}$ piling hammer as shown in Fig. 1.

A full pile driving analysis (PDA), with dynamic measurement of both strains and accelerations near the pile head, was conducted by Lloyds Acoustics Ltd. The hammer drop height was set to $300 \mathrm{~mm}$ for the first $4.6 \mathrm{~m}$ of

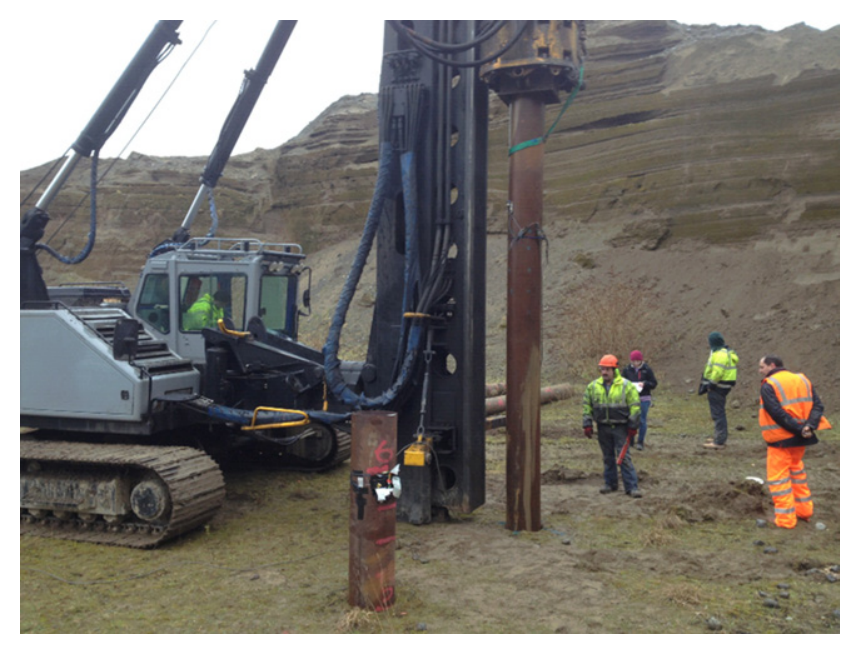

Fig. 1. Driving of the FBG test pile 


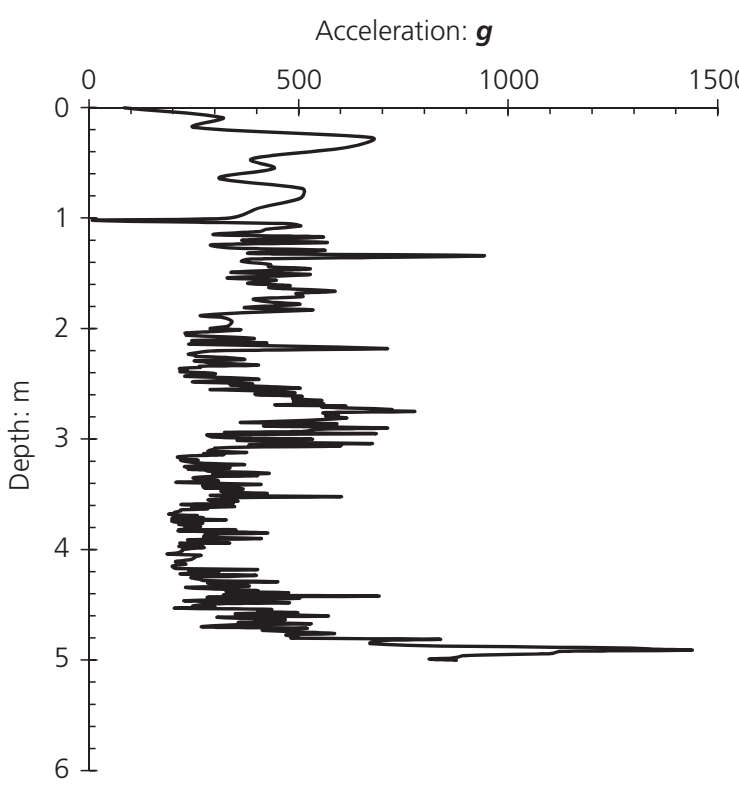

(a)

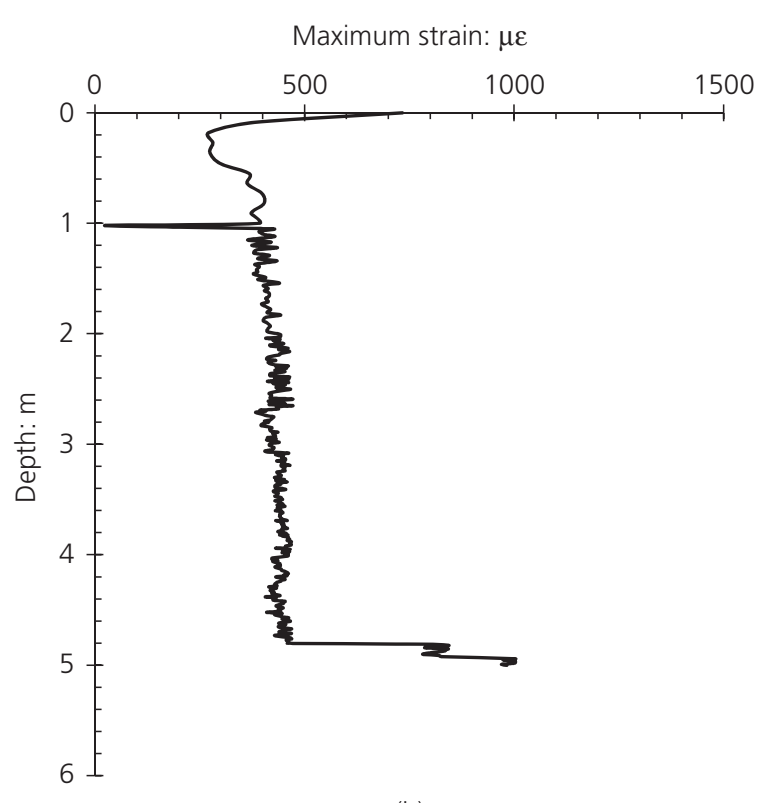

(b)

Fig. 2. (a) Peak acceleration profile and (b) maximum strain near the pile head during driving of FBG test pile measured using dynamic strain gauges

driving. In order to test the survivability of the FBG sensors under higher accelerations and strains, the hammer drop height was increased to over $1 \mathrm{~m}$, over the penetration depth from 4.6 to $5.0 \mathrm{~m}$ below ground level. A profile of peak accelerations with depth is shown in Fig. 2(a), where the maximum acceleration measured was greater than $1400 \mathrm{~g}$. The strain values (as measured by dynamic strain gauges near the pile head) during installation are shown in Fig. 2(b). The maximum strain values were typically around $400 \mu \varepsilon$ when the hammer drop height was set at $300 \mathrm{~mm}$. When the drop height increased to $1 \mathrm{~m}$, maximum strains greater than $1000 \mu \varepsilon$ were measured towards the end of installation. The number of blows for different peak accelerations is shown in Fig. 3. The pile experienced more than 300 blows at greater than $400 \mathrm{~g}$ accelerations and a small number of blows greater than $1000 \mathrm{~g}$.

The performance of the FBG strain sensors during installation is shown in Fig. 4. A comparison of the peak strains measured for each blow from the dynamic PDA strain gauges and the FBG sensors above ground level are shown in Fig. 5. The FBG sensors were logged at $1000 \mathrm{~Hz}$ continuously throughout installation. This logging frequency is significantly less than standard dynamic logging frequencies and therefore does not necessarily capture the maximum strain values associated with individual hammer impacts. However, the following points can be noted.

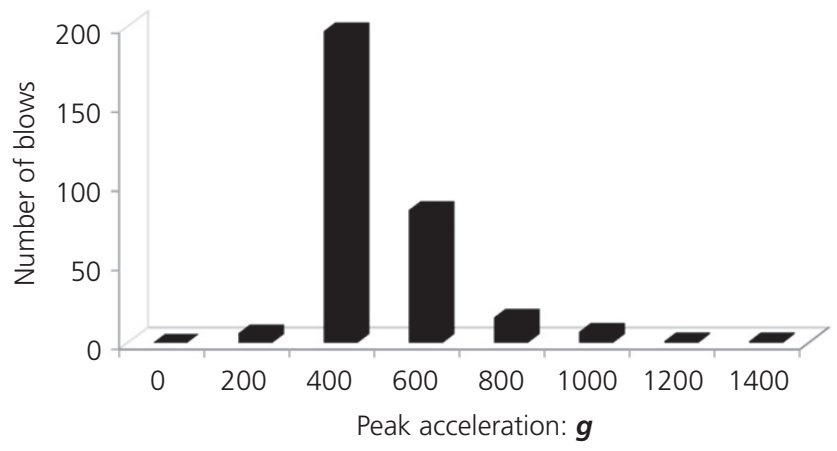

Fig. 3. Number of blows at high accelerations during driving
- The peak compressive strains from the FBG sensors above ground level (Fig. 4(a) and Fig. 5) of $\approx 300-500 \mu \varepsilon$ are in line with those measured from the dynamic strain gauge driving analysis.

- The stability of the FBG sensors is evident from the fact that, between blows, the sensors above ground level (Fig. 4(a)) only deviated by less than $10 \mu \varepsilon$ from the pre-driving zero position once the driving hammer was removed at the end of installation.

- The two sensors near the pile toe (Fig. 4(b)) are constrained by the surrounding soil and are therefore expected to be affected by residual stresses during pile driving. It should be noted that both sensors at the pile toe show comparable deviation from the zero position and, if temperature corrected, these could be taken as a direct measure of the residual strain on the pile.

One week after driving, the FBG test pile was laterally load tested against a $7 \mathrm{~m}$ long reaction pile. The test setup is shown in Fig. 6. In order to accommodate a $36 \mathrm{~mm}$ Dywadag tension loading bar, a $60 \mathrm{~mm}$ slot was burned out of both the test and reaction piles. A $500 \mathrm{kN}$ loading jack with $75 \mathrm{~mm}$ stroke was used to apply the load to the tension bar, which was measured with a $250 \mathrm{kN}$ capacity load cell. In addition, a $1000 \mathrm{kN}$ capacity load cell was placed on the reaction pile to provide a secondary measurement of the applied load. Two linear variable differential transformers (LVDTs) were set up on each pile using two reference beams and magnetic clamps, at 40 and $450 \mathrm{~mm}$ above ground level. A single Seika model N2 inclinometer, with a resolution of $<0.002^{\circ}$ and a measuring range of $\pm 10^{\circ}$, was placed at $40 \mathrm{~mm}$ above ground level on each pile, $90^{\circ}$ radially offset from the line of loading.

The load was applied in $10 \mathrm{kN}$ increments up to $180 \mathrm{kN}$ before the jack travel of $125 \mathrm{~mm}$ was exceeded. The applied moment versus rotation at ground line is plotted in Fig. 7. It is evident that the pile experienced approximately $1.1^{\circ}$ rotation at peak load, but upon unloading this was fully recovered. As the pile was slender $(L / D=15)$ and the toe of the pile is essentially fixed in the ground, this recovery response is expected. The FBG strain readings are plotted in Fig. 8. The two strain sensors above ground level respond 


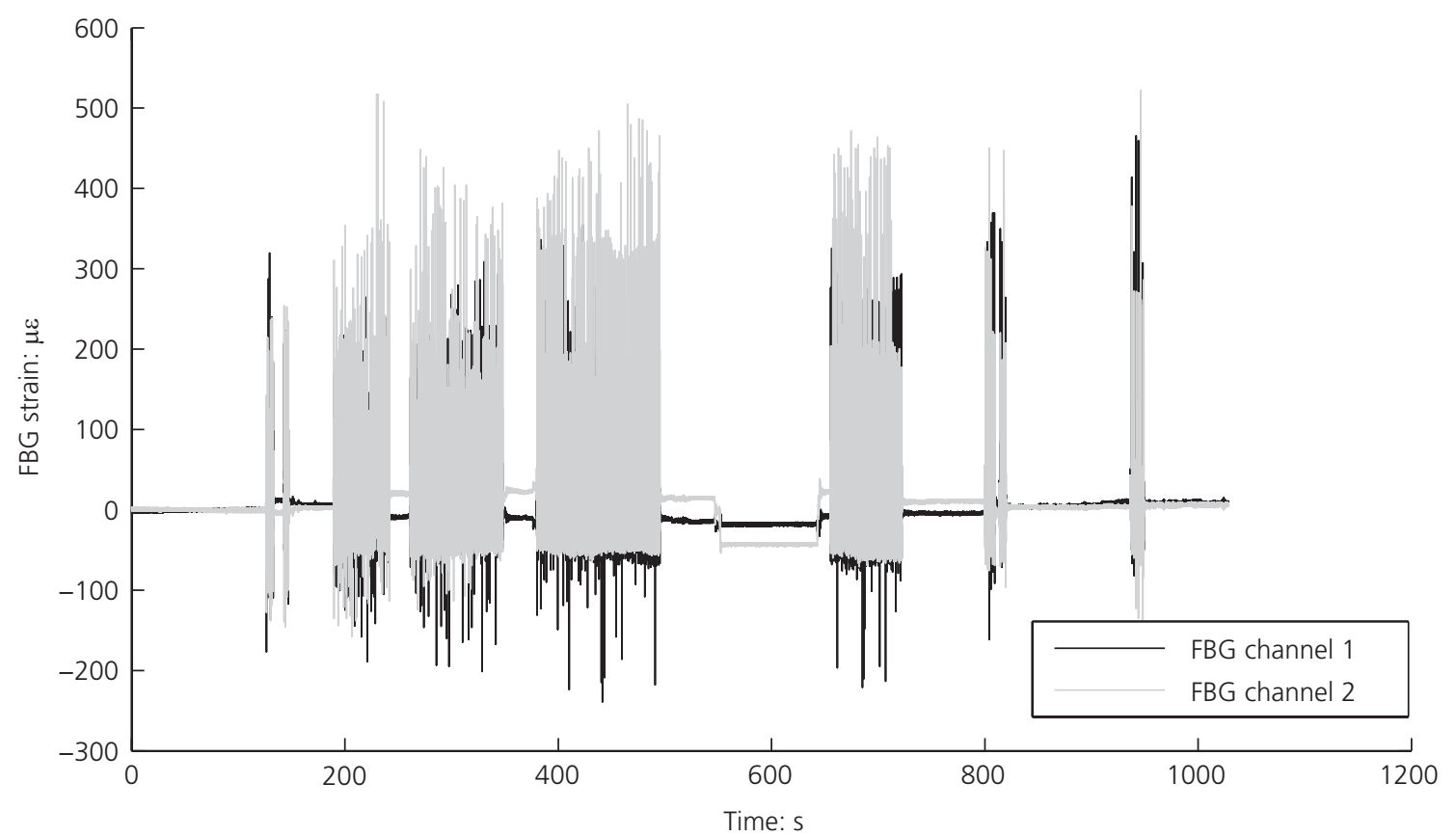

(a)

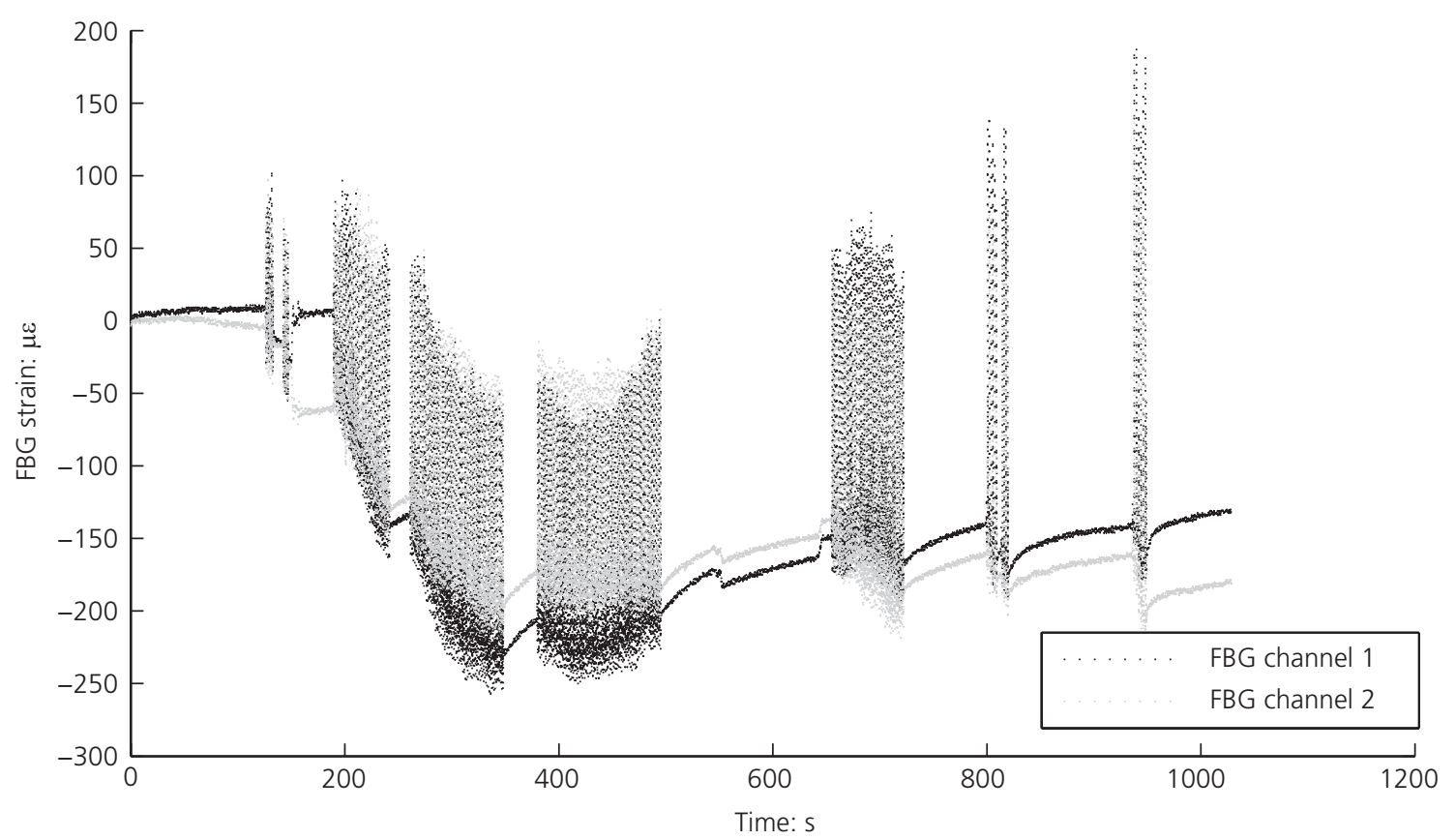

(b)

Fig. 4. Strain measurements from FBG sensors (a) above ground level and (b) near pile toe

well to loading and show large increases in strain during the testing (tension and compression) with maximum strains of $\approx 1000 \mu \varepsilon$ measured on the tensile face and $\approx 780 \mu \varepsilon$ on the compressive face. The asymmetry of tension and compression strains is common during pipe bending due to a shift in the neutral axis towards the inner arc (compression face). In addition, as a point load is applied, some distortion of the pile close to the point of loading may occur, but this effect reduces with distance from the point of loading and is generally not problematic for deriving the bending moment profile away from the point of loading.

In order to compare the applied and measured moments, the average curvature of the pile during loading (as determined from the FBG strain readings) was compared to the applied moment at the upper gauge level. The moment from the FBG readings was determined using

$$
M=E I \Theta
$$

where $M$ is the shaft moment, $E$ is Young's modulus of steel, $I$ is the second moment of inertia of the pile and $\Phi$ is the average curvature of the shaft, which is obtained from the difference between the compressive and tensile strains measured at the same depth of the shaft divided by the distance between the two strain gauges. It is evident from Fig. 9 and Fig. 10 that the moment calculated from the FBG sensors matches very closely with the applied moment 


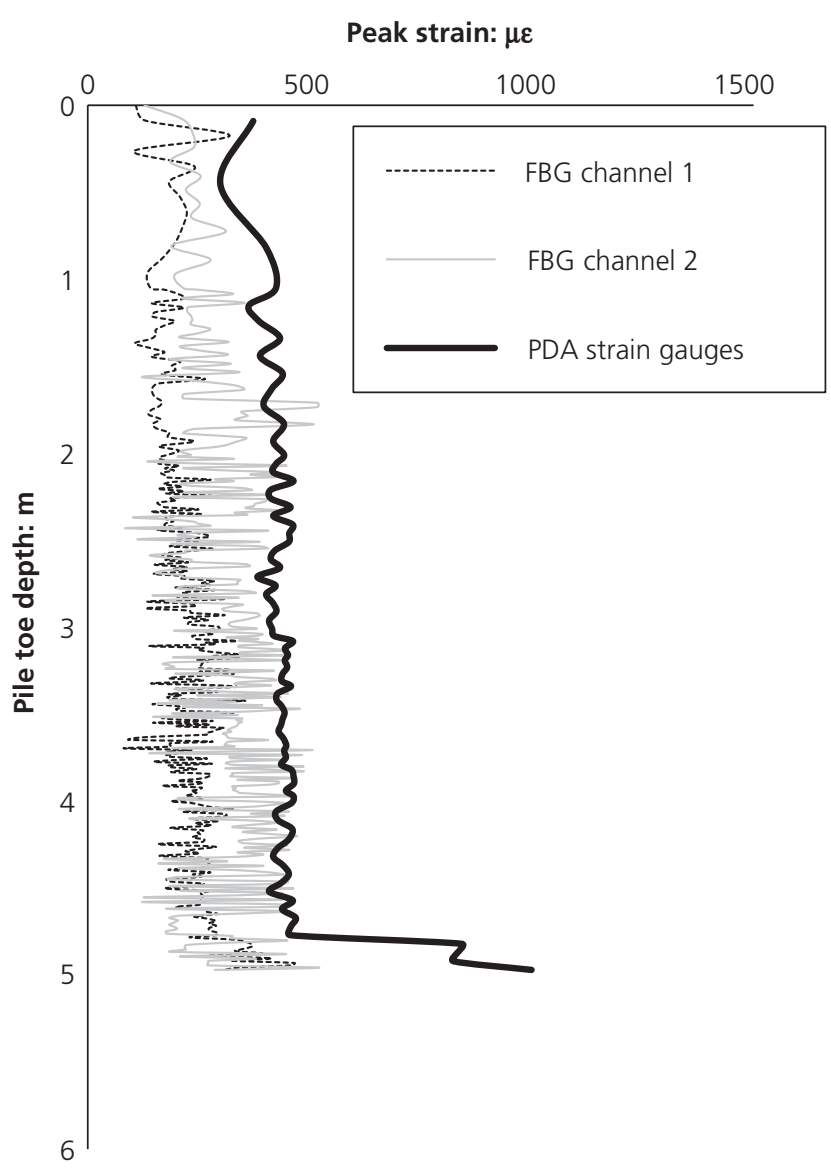

Fig. 5. Comparison of peak strains measured from dynamic PDA strain gauges and FBG sensors above ground level

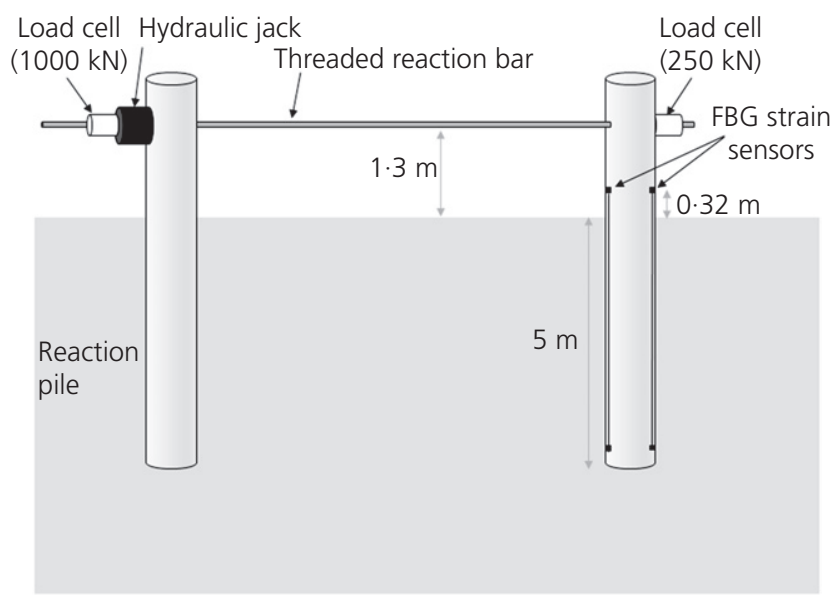

Fig. 6. Load test setup

measured from the $1000 \mathrm{kN}$ load cell (located on the reaction pile). For the $250 \mathrm{kN}$ load cell, the self-weight of the loading bar, plates and hydraulic jack may have resulted in a slight pinch on the load cell for the low load levels, which may explain the mismatch between applied and measured moment during initial loading.

\section{SUMMARY}

This paper has summarised a field trial undertaken to validate the use of FBG strain sensing arrays in driven steel pile applications. A $340 \mathrm{~mm}$ pipe pile was instrumented with two FBG strings and driven to $5 \mathrm{~m}$ below ground level in a

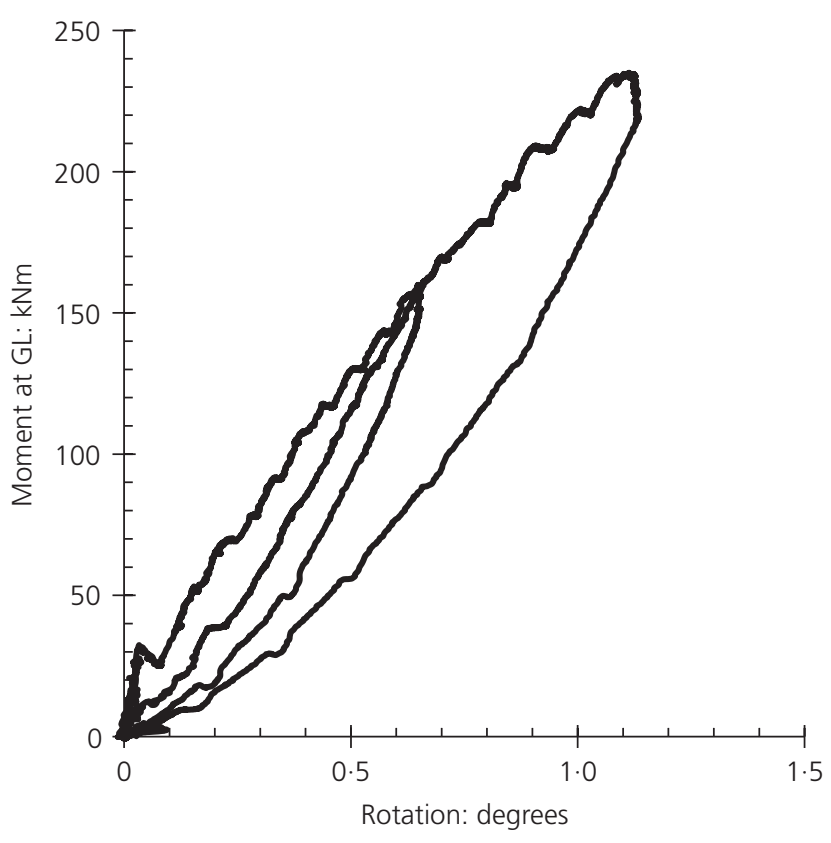

Fig. 7. Moment versus rotation at ground level for test pile

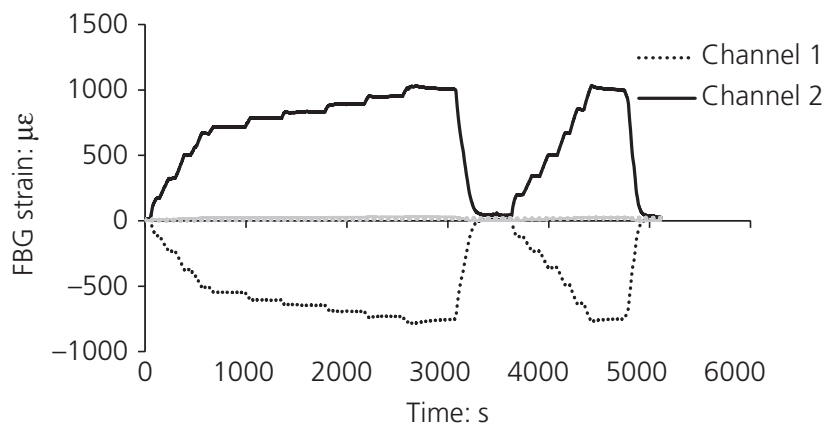

Fig. 8. FBG strain reading during load test

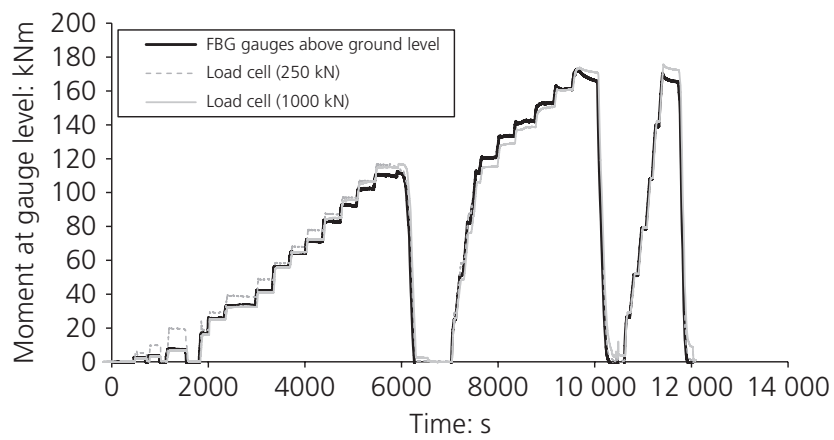

Fig. 9. Applied moment during load test

dense sand deposit. A static lateral load test was performed one week after driving to assess the FBG gauge performance. The following conclusions were drawn.

- The FBG sensors survived the driving process, with peak accelerations of up to $1400 \mathrm{~g}$ and peak strains in the steel of more than $1000 \mu \varepsilon$.

- The gauges above ground level displayed remarkable stability, with less than $10 \mu \varepsilon$ drift from the pre-driving zero position. 


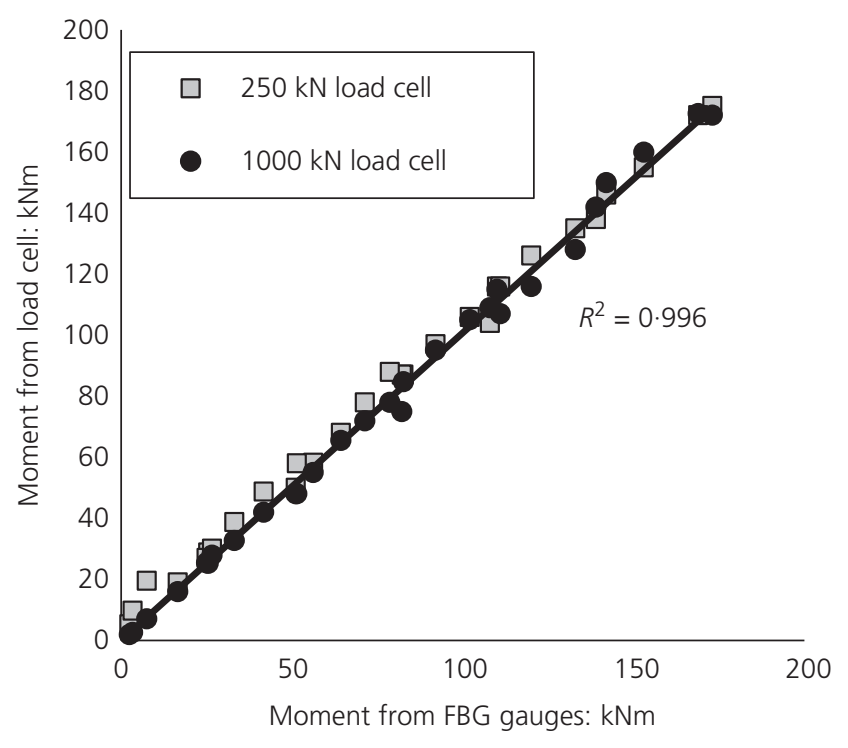

Fig. 10. Applied moment versus measured moment from FBG sensors

- The FBG sensors near the pile toe were shown to move from the zero position during driving, which is attributed to the development of residual loads.

- A post-driving lateral load test indicated an excellent match between the applied moment and the moment derived from the strain gauges above ground level. Due to the slenderness of the pile and the depth of the strain sensors near the pile toe, it is very difficult to accurately assess the applied bending moment at this point. Nevertheless, the gauges near the pile toe responded to loading and indicated good stability throughout testing.

\section{ACKNOWLEDGEMENTS}

This project acknowledges the support received from the Technology Innovation Development Award (TIDA) funded by Science Foundation Ireland and Enterprise Ireland. The financial and technical support of our industry partners, Datum Monitoring, Lloyds Acoustics and Monitor Optics is also greatly appreciated. The authors also acknowledge the generous funding support for PISA by the partners, including the Carbon Trust through the Offshore Wind Accelerator, DONG Energy, Iberdrola, RWE, SSE, Statoil, Statkraft, Vattenfall, Alstom and EDF.

\section{REFERENCES}

Cheung, L., Soga, K., Bennett, P. et al. (2010). Optical fibre strain measurement for tunnel lining monitoring. Proc. Inst. Civ. Eng. - Geotech. Engng 163, No. 3, 119-130.

Doherty, P., Kirwan, L., Gavin, K. et al. (2012). Soil properties at the UCD geotechnical research site at Blessington, Proc. Bridge and Concrete Research in Ireland Conf., Dublin, Ireland 499-504.

Kersey, A. D. \& Morey, W. W. (1993). Multiplexed Bragg grating fibre-laser strain-sensor system with mode-locked interrogation. Electron. Lett. 29, No. 1, 112-114.

Lee, W., Lee, W., Lee, S. \& Salgado, R. (2004). Measurement of pile load transfer using the fiber Bragg grating sensor system. Can. Geotech. J. 41, No. 6, 1222-1232.

Liu, J. \& Zhang, M. (2012). Measurement of residual force locked in open-ended pipe pile using FBG-based sensors. Electron. J. Geotech. Eng. 17.

Tolooiyan, A. \& Gavin, K. (2011). Modelling the cone penetration test in sand using cavity expansion and arbitrary Lagrangian Eulerian finite element methods. Comp. Geotech. 38, No. 4, $482-490$.

Zhu, P., Zhou, Y., Thevenaz, L. \& Jiang, G. (2008). Seepage and settlement monitoring for earth embankment dams using fully distributed sensing along optical fibers. Proc. Int. Conf. of Optical Instrument and Technology (OIT'08), Beijing, China.

\section{WHAT DO YOU THINK?}

To discuss this paper, please email up to 500 words to the editor at journals@ice.org.uk. Your contribution will be forwarded to the author(s) for a reply and, if considered appropriate by the editorial panel, will be published as a discussion. 